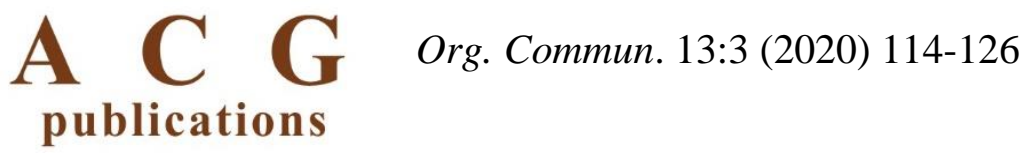

organic communications

\title{
Synthesis of new fatty acid derivatives of oleanane and ursane triterpenoids and investigation of their in vitro cytotoxic effects on 3 T3 fibroblast and PC3 prostate cancer cell lines
}

\author{
Halil Şenol ${ }^{1}$ 1,*, Kübra Çokuludağ ${ }^{2}$, Asude Sena Aktaş $\bigodot^{2}$, \\ Sezen Atasoy $\oplus^{3}$, Aydan Dağ ${ }^{1}$ and Gülaçtı Topçu $\oplus^{4}$ \\ ${ }^{I}$ Bezmiâlem Vakif University Faculty of Pharmacy Department of Pharmaceutical Chemistry, Fatih, \\ 34093, İstanbul, Türkiye \\ ${ }^{2}$ Bezmiâlem Vakif University Faculty of Pharmacy, Fatih, 34093, Istanbul, Türkiye \\ ${ }^{3}$ Bezmiâlem Vakif University Faculty of Pharmacy Department of Biochemistry, Fatih, 34093, \\ Istanbul, Türkiye \\ ${ }^{4}$ Bezmiâlem Vakif University Faculty of Pharmacy Department of Pharmacognosy Fatih 34093, \\ Istanbul, Türkiye
}

(Received Septemeber 02, 2020; Revised September 24,2020; Accepted September 25,2020)

\begin{abstract}
In this study, 12 new oleanane and ursane derivative triterpene compounds, having fatty acids in the form of esters with carbon numbers of $12,13,18,19,24$ and 25 , were synthesized starting from natural products oleanolic

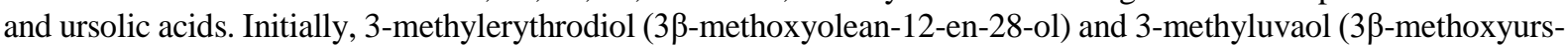
12-en-28-ol) were synthesized from oleanolic acid and ursolic acid, respectively. For this purpose, secondary $\mathrm{OH}$ group at C-3 of oleanolic and ursolic acids were protected as methyl ether and, then, their carboxylic acid moieties were reduced by aluminum hydride. New fatty acid derivatives $\mathbf{5 a - f}$ and $\mathbf{8 a - f}$ were synthesized through the reaction of 3-methylerythrodiol/3-methyluvaol and corresponding fatty acid halides. In vitro cytotoxic activities of the all synthesized compounds were investigated on 3T3 fibroblast cells and PC3 prostate cancer cell lines. While all the compounds showed at least $70 \%$ inhibition on PC 3 prostate cancer cells at a concentration of $25 \mu \mathrm{M}$, they had average of 50\% inhibition on 3T3 fibroblast human healthy cells at the same concentration. Compounds $\mathbf{5 c}$ and $\mathbf{8 c}$ demonstrated the least toxic effect on $3 \mathrm{~T} 3$ fibroblast human healthy cells and the highest toxic effect on PC 3 prostate cancer cells at a concentration of $12.5 \mu \mathrm{M}$. Moreover, compounds $8 \mathbf{c}$ and $8 \mathbf{e}$ had the least toxic effect on $3 \mathrm{~T} 3$ fibroblast human healthy cells and the highest toxic effect on PC3 prostate cancer cells at the same concentration.
\end{abstract}

Keywords: Oleanolic acid; ursolic acid; triterpenoids; prostate cancer; MTT, cytotoxicity. @2020 ACG Publications. All right reserved.

\section{Introduction}

Cancer is a group of diseases characterized by an uncontrolled growth and spread of abnormal cells. If the spread is not controlled, it can result in death. Compared to normal cells, cancer cells damage DNA and do not have a life cycle like normal cells. Instead, the cancerous cells continue to make new cells having the same damaged DNA. Invading other tissues may end up with death unless the spread is

* Corresponding author: E-mail: hsenol@bezmialem.edu.tr, Phone: + 90212523 2288-3364; Fax: + 902125332326 
controlled $^{1-4}$. Even though cancer can affect people from all ages, the risk of being effected by cancer generally increases with age. In 2007, about $13 \%$ of all human deaths worldwide, which means 7.9 million, resulted from cancer. There are approximately 75 million people worldwide living with the diagnosis of cancer, and this number is estimated to reach 21 million per year in 2030. In addition, 17 million patients die each year from cancer ${ }^{5-9}$.

The cancerous cells can enter bloodstream/lymph vessels and travel to other parts of body, which is called metastasis. Different types of cancers can act very differently in terms of growth rates or their response to various treatments. Some inherited genetic mutations, hormones or immune characteristics can cause cancer. Moreover, permanent DNA damage by external factors such as radiation, toxic chemicals, tobacco, infectious organisms, and an unhealthy diet may cause cancer as well ${ }^{1-4}$.

Prostate cancer is the most commonly diagnosed cancer type and the second most common cause of cancer death among men in US. It accounts for about 1 in 4 newly diagnosed cancers each year. Approximately 250,000 new cases of prostate cancer diagnosed in US in 2010. In the same year, 32,000 men were expected to die from prostate cancer ${ }^{1}$. Most common types of cancer in men in Turkey, lung, prostate, colon, bladder and stomach cancers, respectively. However, while women in Turkey in the incidence of cancer in the world average, the rate for males is higher than the world average. In the USA and Europe in the incidence of cancer in both men and women is much higher as compared to Turkey ${ }^{8}$ ${ }^{10}$. As there is no enough information about the risk factors and the causes of prostate cancer, it has many unique characteristics compared to other common cancer forms. Age, ethnicity and genetic factors as well as diets, exercise, sexual activity, smoking, and overweight increase the risk. It has been known that depletion of androgens protects men from prostate cancer; on the other hand, increase of androgen level does not cause prostate cancer compared to low level of androgens ${ }^{10-12}$.

Triterpenoids have various biological activities as one of the main secondary metabolites of plants. Anti-oxidant, antibacterial, anti-inflammatory, antiviral, cytotoxic, antitumor/anticancer, etc. activities of oleanane, ursane and lupane triterpenoids have already been determined ${ }^{13-17}$. As a result of Topcu and her research group's studies for many years on plants particularly rich in oleanane and ursane triterpenoids, over 50 triterpenoids were isolated and their structures were elucidated. They were determined to have antibacterial, anti-oxidant, cytotoxic and anticholinesterase activities ${ }^{18-28}$. Moreover, the same group also isolated a series of polyhydroxylated oleanane and ursane triterpenoids from some Salvia species during recently studies, and determined their strong Nuclear Factor Kappa B (NF-кB) inhibition activity by in silico studies and cell culture assays ${ }^{29-31}$. A few triterpenes from the same series were further investigated by NCI (National Cancer Institute-USA) against 60 cell lines in vitro for their cytotoxic activity, two of which, $1 \beta, 2 \alpha, 3 \beta, 11 \alpha$-tetrahydroxy-urs-12-ene, $3 \beta$-acetate, and $1 \beta, 2 \alpha, 3 \beta, 11 \alpha$ tetrahydroxy-olean-12-ene, $3 \beta$-acetate, were found to be highly cytotoxic against renal, non-small cell lung and breast cancer cell lines ${ }^{29}$.

Many research groups from different countries, including Topçu, have been investigated ursolic acid and oleanolic acid derivatives. These compounds have shown anticancer, antiviral, anticholinesterase and many other activities ${ }^{14,16,29,32}$. In addition to ursane and oleanane derivatives, the cytotoxic, antiviral and even NF- $\kappa \mathrm{B}$ inhibition activities of some lupane derivatives, such as betulinic acid and lupeol, were reported and related studies are still continuing intensively ${ }^{33}$. Furthermore, mechanistic studies about inhibition of NF- $\mathrm{kB}$ signaling pathway by different terpenes were reported ${ }^{34}$, 35 .

Today, there is a high requirement for new anticancer drugs because of the side effects of chemotherapeutics. Despite increasing number of anticancer agents, low selectivity, low bioavailability and multiple drug resistance are significant barriers to successful cancer treatment ${ }^{36}$. Thus, discovery of potent and selective anticancer agents is important. The aim of this study is to develop a potent anticancer drug for prostate cancer. Both terpenes and fatty acids are very important chemicals for living organism. A large number of fatty acids are metabolized in living organisms and almost all of them have unique functions. Combination of biologically active natural compounds and biologically active chemical substances are called hybrid molecules. In this study, a series of hybrid molecules was synthesized and their biological activities were investigated. 


\section{Experimental}

\subsection{Chemical Material and Apparatus}

All solvents, chemicals and other supplies used in the experiments were purchased from Merck, Sigma Aldrich, TCI Chemicals and other suppliers. Although commercially available chemicals and solvents have high purity, purification procedures were performed as described in the literature, when necessary ${ }^{37-39}$. Dichloromethane (Merck, 106049), dimethyl sulfoxide (Sigma-Aldrich, M81802), dimethyl sulfoxide-D6 (Merck, 103591), ethanol (Merck, 100983), ethyl acetate (Merck, 100789), hexane (Merck, 104374), chloroform (Merck, 102445), chloroform-D1 (Merck, 102446), lauroyl chloride (Sigma-Aldrich, 156930), lithium aluminum hydride (Sigma-Aldrich, 686034), methanol (Merck, 106009), methyl iodide (Sigma-Aldrich, 289566), nonadecanoic acid (TCI Chemicals, N0283), oleanolic acid (Carbone Scientific, C-22557), pentacosanoic acid (TCI Chemicals, P0882), cerium (IV) sulfate (Sigma-Aldrich, 359009), silica gel 60-(Gypsum containing- $F_{254}$ ) (Merck, 107749), silica gel 60 for column chromatography (70-230 mesh ASTM) (Merck, 107734), silica gel 60 - TLC (20x20 Al plate - $\mathrm{F}_{254}$ ) (Merck, 105554), silicone oil (ZAG Chemistry, AK350), sodium hydroxide (Merck, 106462), sodium hydride (in 60\% mineral oil) (Sigma-Aldrich, 452912), sodium sulfate (Merck, 106649), stearic acid (Merck, 800673), tetrahydrofuran (Merck , 107025), tetracosanoic acid (TCI Chemicals, T0076), thionyl chloride (Sigma-Aldrich, 320536), tridecanoic acid (TCI Chemicals, T0412), ursolic acid (BOC Sciences, B0084-077000).

In general, column chromatography was performed for chromatographic separations and purifications. In column chromatography, silica gel was used as a stationary phase, mixtures of ethyl acetate and hexane were used as mobile phases. Progress of the experiments and the column chromatographies were monitored by thin layer chromatography (TLC), and detection of spots was conducted using UV light, cerium(IV)sulfate solution $10 \%$ in sulfuric acid and heating in stove at 100 ${ }^{\circ} \mathrm{C}$. Nuclear magnetic resonance (NMR) analyses $\left({ }^{1} \mathrm{H}\right.$-NMR and ${ }^{13} \mathrm{C}$-APT NMR) were used for determination of chemical structures. HRMS analyses were performed for determination of molecular weight.

Melting points were determined by Stuart SMP30 melting point apparatus. ${ }^{1} \mathrm{H}-\mathrm{NMR}$ and ${ }^{13} \mathrm{C}-$ APT NMR spectra were recorded by Bruker Avance NEO NMR Spectrometer at 500 and $125 \mathrm{MHz}$, respectively. Coupling constant values were given in Hertz $(\mathrm{Hz})$. Chemical shifts were reported in $\delta$ (parts per million) units relative to the internal standard tetramethylsilane $(\delta=0.00 \mathrm{ppm})$ and the peak splits were described as follows: $\mathrm{s}$ (singlet), $\mathrm{d}$ (doublet), $\mathrm{t}$ (triplet), $\mathrm{q}$ (quartet), $\mathrm{m}$ (multiplet), bs (broad singlet), dd (doublet of doublet) and dt (doublet of triplet). HRMS spectra were recorded using ESI technique by Thermo Fischer Scientific Q Exactive ${ }^{\mathrm{TM}}$ Hybrid Quadrupole-Orbitrap $^{\mathrm{TM}}$ Mass Spectrometer.

\subsection{Cell Culture}

Human prostat adenocarcinoma PC3 and mouse fibroblast 3T3 cell lines were used in this study. PC3 and 3T3 were grown in DMEM/F12 and DMEM, respectively, both supplemented with 10\% FBS and $100 \mathrm{U} / \mathrm{mL}$ of penicillin-streptomycin at $37^{\circ} \mathrm{C}$ in a humidified incubator with $5 \% \mathrm{CO}_{2}$. After reaching $80 \%$ confluency, the cells were detached using $0.25 \%$ trypsin-EDTA. For further experiments, cells were resuspended in the growth medium after collection and centrifugation.

\subsection{MTT Assay}

A MTT (3-(4,5-dimethylthiazol-2-yl)-2,5-diphenyltetrazolium bromide) assay was used to assess cell viability. Briefly, $5 \times 103$ cells were seeded into flat-bottom 96-well plate with growth medium. After 24 $\mathrm{h}$ incubation, it was treated with increasing doses of samples for 24 hour and the assay was conducted. The absorbance values were recorded at $540 \mathrm{~nm}$ using microplate reader. All the experiments were carried out in triplicates, and the results were presented as a mean \pm standard deviation. 


\subsection{Chemistry}

\subsubsection{Synthesis of 3-methyloleanolic acid methyl ester (3) and 3-methylursolic acid methyl ester (6)}

A round bottom flask was charged with freshly distilled THF $(300 \mathrm{~mL})$ and added $\mathrm{NaH}(60 \%$, $175 \mathrm{mmol}, 7 \mathrm{~g}, 8$ equiv.) under an inert atmosphere. After heating the mixture for 30 minutes, oleanolic acid or ursolic acid (22 mmol, $10 \mathrm{~g}, 1$ equiv.) and $\mathrm{MeI}(260 \mathrm{mmol}, 16 \mathrm{~mL}, 12$ equiv.) were added and refluxed for 2 days, after which excess sodium hydride was carefully hydrolyzed with water $(15 \mathrm{~mL})$ in an ice bath. The reaction solvent was removed under reduced pressure and the residue was washed with water $(3 \times 300 \mathrm{~mL})$. Organic layer was dried over $\mathrm{Na}_{2} \mathrm{SO}_{4}$ and the solvent removed under reduced pressure. The crude product was purified by column chromatography packed with silica gel eluting with a mixture of ethyl acetate and hexane (1: 9) to obtain the pure compounds $\mathbf{3}$ (white solid, $9.0 \mathrm{~g}, 87 \%$ yield) and $\mathbf{6}$ (white solid, $8.5 \mathrm{~g}, 82 \%$ yield).

Compound 3: m.p.: $168{ }^{\circ} \mathrm{C}$; ${ }^{1} \mathrm{H}-\mathrm{NMR}\left(500 \mathrm{MHz}, \mathrm{CDCl}_{3}\right) \delta: 5.28(1 \mathrm{H}, \mathrm{t}, J=3.4 \mathrm{~Hz}$, olefinic H-12), 3.61 ( $3 \mathrm{H}, \mathrm{s}, \mathrm{HC}-\mathrm{OCH} 3), 3.34\left(3 \mathrm{H}, \mathrm{s}, \mathrm{O}=\mathrm{C}-\mathrm{OCH}_{3}\right), 2.85(1 \mathrm{H}, \mathrm{dd}, J=4.4,13.8 \mathrm{~Hz}, \mathrm{H}-18), 2.65(1 \mathrm{H}, \mathrm{dd}, J=4.0$, $11.6 \mathrm{~Hz}, \mathrm{H}-3) .{ }^{13} \mathrm{C}-\mathrm{NMR}\left(125 \mathrm{MHz}, \mathrm{CDCl}_{3}\right) \delta: 177.6,143.1,121.7,87.9,56.8,55.0,50.8,46.9,46.0$, 45.2, 40.9, 40.6, 38.6, 38.0, 37.6, 36.3, 33.1, 32.4, 31.9, 31.7, 30.0, 27.4, 27.0, 25.2, 22.9, 22.7, 22.3, 21.3, 17.5, 16.1, 15.6, 14.6.; HRMS: Molecular Formula: $\mathrm{C}_{32} \mathrm{H}_{52} \mathrm{O}_{3}$; Exact Mass: 484.39165; Calculated $\mathrm{m} / \mathrm{z},[\mathrm{M}+1]+:$ 485.39947; Experimental: $\mathrm{m} / \mathrm{z},[\mathrm{M}+1]+: 485.39954$

Compound 6: m.p.: $165{ }^{\circ} \mathrm{C}$; ${ }^{1} \mathrm{H}-\mathrm{NMR}\left(500 \mathrm{MHz}, \mathrm{CDCl}_{3}\right), \delta$ ppm: $5.18(\mathrm{t}, J=3.61, \mathrm{~Hz}, 1 \mathrm{H}), 3.54(\mathrm{~s}$, $3 \mathrm{H}), 3.29(\mathrm{~s}, 3 \mathrm{H}), 2.59(\mathrm{dd}, J=11.72,4.32 \mathrm{~Hz}, 1 \mathrm{H}), 2.16(\mathrm{~d}, J=11.07 \mathrm{~Hz}, 1 \mathrm{H}), 1.93(\mathrm{dt}, J=13.42$, $4.54 \mathrm{~Hz}, 1 \mathrm{H}), 1.84(\mathrm{dd}, J=8.86,3.64 \mathrm{~Hz}, 2 \mathrm{H}), 1.83-1.17$ (peak groups belong to aliphatic region, $18 \mathrm{H}$ ), $1.05(\mathrm{~s}, 3 \mathrm{H}), 0.96(\mathrm{~s}, 3 \mathrm{H}), 0.91(\mathrm{~d}, J=6.19 \mathrm{~Hz}, 3 \mathrm{H}), 0.89(\mathrm{~s}, 3 \mathrm{H}), 0.71(\mathrm{~s}, 3 \mathrm{H}) ;{ }^{13} \mathrm{C}-\mathrm{NMR}(125 \mathrm{MHz}$, $\left.\mathrm{CDCl}_{3}\right), \delta$ ppm: $177.92,137.99,125.48,88.53,57.42,55.63,52.73,51.34,47.93,41.83,39.37,38.91$, $38.73,38.53,38.38,36.84,36.50,32.84,30.53,30.19,28.03,28.87,24.09,23.47,23.20,21.89,21.10$, 18.07, 16.94, 16.79, 16.26, 15.30; HRMS: Molecular Formula: $\mathrm{C}_{32} \mathrm{H}_{52} \mathrm{O}_{3}$; Exact Mass: 484.39165; Calculated $m / z[\mathrm{M}+1]^{+}:$485.39947; Experimental: $\mathrm{m} / z,[\mathrm{M}+1]^{+}: 485.39990$

\subsubsection{Synthesis of 3-methyl erythrodiol (4) and 3-methyluvaol (7)}

Two necked round-bottom flask was charged with freshly distilled tetrahydrofuran (THF). One of the necks was attached to the nitrogen atmosphere and the other neck was fitted with a glass cap. $\mathrm{LiAlH}_{4}\left(165 \mathrm{mmol}, 6.25 \mathrm{~g}, 10\right.$ equiv.) was added quickly and the mixture was cooled to $-18^{\circ} \mathrm{C}$ in a saltice bath. After stirring for 15 minutes, compound $\mathbf{3}$ or compound $\mathbf{6}$ ( $16.5 \mathrm{mmol}, 8 \mathrm{~g}, 1$ equiv.) was added under nitrogen atmosphere and the mixture was refluxed for 24 hours. The progress of the reaction was followed by TLC. After $24 \mathrm{~h}$, water $(5 \mathrm{~mL})$ was added. The white aluminum complex, which became gel, was separated by vacuum filtration, then the aqueous solvent was removed under reduced pressure. The residue was washed with water $(3 \times 300 \mathrm{~mL})$, the organic layer was dried over $\mathrm{Na}_{2} \mathrm{SO}_{4}$ and the solvent was removed under reduced pressure to obtain the pure compounds 4 (from 3 ) and $\mathbf{7}$ (from 6) as white solids (4: $6.95 \mathrm{~g}, 92 \%$ yield; 7: $6.6 \mathrm{~g}, 88 \%$ ).

Compound 4: m.p.: $239^{\circ} \mathrm{C} ;{ }^{1} \mathrm{H}-\mathrm{NMR}\left(500 \mathrm{MHz}, \mathrm{CDCl}_{3}\right) \delta: 5.18(\mathrm{t}, J=3.55 \mathrm{~Hz}, 1 \mathrm{H}), 3.53(\mathrm{~d}, J=10.90$ $\mathrm{Hz}, 1 \mathrm{H}), 3.18(\mathrm{~d}, J=10.90 \mathrm{~Hz}, 1 \mathrm{H}), 3.34(\mathrm{~s}, 3 \mathrm{H}), 2.65(\mathrm{dd}, J=11.70,4.29 \mathrm{~Hz}, 1 \mathrm{H}), 0.98(\mathrm{~s}, 3 \mathrm{H}), 0.93$ (s, 3H), 0.92 (s, 3H), 0.87 (s, 3H), $0.86(\mathrm{~s}, 3 \mathrm{H}), 0.77$ (s, 3H); ${ }^{13} \mathrm{C}-\mathrm{NMR}\left(125 \mathrm{MHz}, \mathrm{CDCl}_{3}\right) \delta: 144.30$, $122.42,88.72$, 69.63, 57.58, 55.78, 47.63, 46.54, 42.40, 41.75, 39.87, 38.76, 38.57, 36.97, 34.15, 33.26, $32.64,31.08,30.99,28.17,25.98,25.59,23.66,23.61,22.09,22.05,18.29,16.79,16.39,15.54$; HRMS: Molecular Formula: $\mathrm{C}_{31} \mathrm{H}_{52} \mathrm{O}_{2}$; Exact Mass: 456.39673; Calculated $m / z[\mathrm{M}+1]^{+}:$457.40456; Experimental: $m / z[\mathrm{M}+1]^{+}: 457.40298$

Compound 7: m.p.: $217^{\circ} \mathrm{C} ;{ }^{1} \mathrm{H}-\mathrm{NMR}\left(500 \mathrm{MHz}, \mathrm{CDCl}_{3}\right), \delta$ ppm: $5.13(\mathrm{t}, J=3.59 \mathrm{~Hz}, 1 \mathrm{H}), 3.52(\mathrm{~d}, J$ $=10.96 \mathrm{~Hz}, \mathrm{~A}$ part of AB system, $1 \mathrm{H}), 3.35(\mathrm{~s}, 3 \mathrm{H}), 3.18(\mathrm{~d}, J=10.96 \mathrm{~Hz}, \mathrm{~B}$ part of AB system, $1 \mathrm{H})$, $2.66(\mathrm{dd}, J=11.72,4.33 \mathrm{~Hz}, 1 \mathrm{H}), 1.90-1.14$ (peak groups belong to aliphatic region, $22 \mathrm{H}), 1.08(\mathrm{~s}, 3 \mathrm{H})$, 
$0.97(\mathrm{~s}, 3 \mathrm{H}), 0.97(\mathrm{~s}, 3 \mathrm{H}), 0.93(\mathrm{~d}, J=8.17 \mathrm{~Hz}, 3 \mathrm{H}), 0.81(\mathrm{t}, J=5.85 \mathrm{~Hz}, 3 \mathrm{H}), 0.76(\mathrm{~s}, 3 \mathrm{H}) ;{ }^{13} \mathrm{C}-\mathrm{NMR}$ $\left(125 \mathrm{MHz}, \mathrm{CDCl}_{3}\right), \delta$ ppm: 138.71, 125.08, 88.67, 69.90, 57.58, 55.72, 54.02, 47.66, 42.02, 40.04, 39.42 , 39.35, 38.72, 38.69, 38.00, 36.88, 35.18, 32.83, 30.63, 28.15, 25.99, 23.42, 23.30, 22.07, 21.36, 18.22, 17.38, 16.79, 16.39, 15.69; HRMS: Molecular Formula: $\mathrm{C}_{31} \mathrm{H}_{52} \mathrm{O}_{2}$; Exact Mass: 456.39673; Calculated $m / z[\mathrm{M}+1]^{+}: 457.40456$; Experimental: $\mathrm{m} / z[\mathrm{M}+1]^{+}: 457.40363$

\subsubsection{General Synthesis of Fatty Acid Chlorides}

The corresponding fatty acid (4 g, 1 equiv.) was dissolved in chloroform $(150 \mathrm{~mL})$ in a round bottom flask. Then, $\mathrm{SOCl}_{2}$ (4 equiv.) was added and the mixture was refluxed for 8 hours. When the reaction was complete, the solvent and excess thionyl chloride were removed under vacuum by heating the mixture. Thus, the acyl halide of the corresponding fatty acid was obtained as pure. According to ${ }^{13} \mathrm{C}$-APT NMR spectrum of the acyl halides, the carboxylic acid group was completely converted to acyl halides. In NMR the signal of carboxylic acid carbon, resonating at $180 \mathrm{ppm}$, shifted to $173 \mathrm{ppm}$ in acyl halides. Since the acyl halides used as intermediate products in this study, NMR spectra of only one acyl halides (pentacosanoyl chloride) is given in supplementary materials part.

Pentacosanoyl chloride: ${ }^{1} \mathrm{H}$ NMR $\left(500 \mathrm{MHz}, \mathrm{CCl}_{3}\right) \delta 2.81(\mathrm{t}, J=7.3 \mathrm{~Hz}, 2 \mathrm{H}), 1.64(\mathrm{p}, J=7.3 \mathrm{~Hz}, 2 \mathrm{H})$, $1.30-1.14(\mathrm{~m}, 42 \mathrm{H}), 0.81(\mathrm{t}, J=6.9 \mathrm{~Hz}, 3 \mathrm{H}) ;{ }^{13} \mathrm{C} \mathrm{NMR}\left(125 \mathrm{MHz}, \mathrm{CDCl}_{3}\right) \delta 172.84,46.10,30.92,28.70$, 28.66, 28.64, 28.60, 28.59, 28.51, 28.46, 28.36, 28.32, 28.26, 28.14, 28.06, 27.41, 13.11.

\subsubsection{General Syntheses of Triterpene - Fatty Acid Esters 5a-f and 8a-f}

A round bottom flask was charged with freshly distilled THF $(150 \mathrm{~mL})$ and added $\mathrm{NaH}(60 \%$, (0.2 g, 8.8 mmol, 4 equiv.) under an inert atmosphere. Erythrodiol-3-methyl ether (4) or uvaol-3-methyl ether (7) $(1 \mathrm{~g}, 2.2 \mathrm{mmol}, 1$ equiv.) was added and stirred for 30 minutes at reflux temperature. After 30 minutes, the acyl halide ( $4.4 \mathrm{mmol}, 2$ equiv.) of the corresponding fatty acid was added and the mixture was refluxed for 24-48 hours. TLC analysis was performed to monitor the progress of the reaction, after which the reaction flask was transferred to an ice bath and water was added dropwise. When the excess sodium hydride was completely hydrolyzed, the reaction solvent was removed under reduced pressure, the residue was washed with water $(3 \mathrm{X} 300 \mathrm{~mL})$ and the crude product was extracted with chloroform $(3 \mathrm{X} 250 \mathrm{~mL})$. The organic layer was dried over $\mathrm{Na}_{2} \mathrm{SO}_{4}$ and filtered. Silica gel $(10 \mathrm{~g})$ was added to the organic layer and the solvent was removed under reduced pressure. The final mixture was added into a column chromatography, filled with silica gel, and vacuum filtered using hexane as an eluting solvent to remove apolar impurities such as oil. The column chromatography was continued with ethyl acetate and hexane gradient from 1:19 to 1:10 ratio. The collected fractions were analyzed to obtain the corresponding pure products 5a-f and 8a-f.

Compound 5a: m.p.: $182{ }^{\circ} \mathrm{C}$; White solid, $1.20 \mathrm{~g}, 86 \%$ yield; ${ }^{1} \mathrm{H}$ NMR $\left(500 \mathrm{MHz}, \mathrm{CDCl}_{3}\right) \delta 5.13(\mathrm{t}, J$ $=3.6 \mathrm{~Hz}, 1 \mathrm{H}), 3.94(\mathrm{~d}, J=11.0 \mathrm{~Hz}, 1 \mathrm{H}), 3.64(\mathrm{~d}, J=11.1 \mathrm{~Hz}, 1 \mathrm{H}), 3.29(\mathrm{~s}, 3 \mathrm{H}), 2.59(\mathrm{dd}, J=11.7,4.3$ $\mathrm{Hz}, 1 \mathrm{H}), 2.24(\mathrm{t}, J=7.3 \mathrm{~Hz}, 2 \mathrm{H}), 1.99(\mathrm{dd}, J=13.6,4.6 \mathrm{~Hz}, 1 \mathrm{H}), 1.90-1.27$ (multiple peak group of aliphatic region, 22H), 1.23-1.20 (m, fatty acid side chain, $20 \mathrm{H}), 1.09(\mathrm{~s}, 3 \mathrm{H}), 0.91(\mathrm{~s}, 3 \mathrm{H}), 0.88(\mathrm{~s}, 3 \mathrm{H})$, $0.86(\mathrm{~s}, 3 \mathrm{H}), 0.82(\mathrm{~s}, 3 \mathrm{H}), 0.81(\mathrm{t}, J=6.9 \mathrm{~Hz}, 3 \mathrm{H}), 0.80(\mathrm{~s}, 3 \mathrm{H}), 0.70(\mathrm{~s}, 3 \mathrm{H}) ;{ }^{13} \mathrm{C}$ NMR $(125 \mathrm{MHz}$, $\left.\mathrm{CDCl}_{3}\right) \delta 173.98,143.64,122.91,88.64,70.47,57.54,55.75,47.59,46.26,42.49,41.62,39.79,38.71$, 38.52 , 36.93, 35.84, 34.55, 34.02, 33.19, 32.55, 31.95, 31.47, 30.91, 29.66, 29.64, 29.56, 29.37, 29.32, 29.19, 28.12, 25.99, 25.57, 25.18, 23.60, 23.56, 22.72, 22.34, 22.02, 18.22, 16.71, 16.35, 15.49, 14.16; HRMS: Molecular Formula: $\mathrm{C}_{43} \mathrm{H}_{74} \mathrm{O}_{3}$; Exact Mass: 638.56380; Calculated $\mathrm{m} / \mathrm{z}[\mathrm{M}+1]^{+}$: 639.57162; Experimental: $\mathrm{m} / \mathrm{z}[\mathrm{M}+1]^{+}: 639.57410$

Compound 5 b: m.p.: $181^{\circ} \mathrm{C}$; White solid, 1.18 g, $82 \%$ yield; ${ }^{1} \mathrm{H}$ NMR $\left(500 \mathrm{MHz}, \mathrm{CDCl}_{3}\right) \delta 5.20(\mathrm{t}, J=$ $3.7 \mathrm{~Hz}, 1 \mathrm{H}), 4.08(\mathrm{~d}, J=11.0 \mathrm{~Hz}, 1 \mathrm{H}), 3.78(\mathrm{~d}, J=11.0 \mathrm{~Hz}, 1 \mathrm{H}), 3.35(\mathrm{~s}, 3 \mathrm{H}), 2.66(\mathrm{dd}, J=11.6,4.3$ $\mathrm{Hz}, 1 \mathrm{H}), 2.37(\mathrm{t}, J=7.4 \mathrm{~Hz}, 2 \mathrm{H}), 2.14-1.36$ (multiple peak group of aliphatic region, $21 \mathrm{H}), 1.26(\mathrm{~m}$, fatty acid side chain, 22H), $1.16(\mathrm{~s}, 3 \mathrm{H}), 0.98(\mathrm{~s}, 3 \mathrm{H}), 0.94(\mathrm{~s}, 3 \mathrm{H}), 0.93(\mathrm{~s}, 3 \mathrm{H}), 0.88(\mathrm{~s}, 3 \mathrm{H}), 0.86(\mathrm{~s}$, $3 \mathrm{H}), 0.81(\mathrm{t}, J=6.9 \mathrm{~Hz}, 3 \mathrm{H}), 0.77(\mathrm{~s}, 3 \mathrm{H}) ;{ }^{13} \mathrm{C} \mathrm{NMR}\left(126 \mathrm{MHz}, \mathrm{CDCl}_{3}\right) \delta 170.13,143.45,123.09,88.64$, 71.56, 59.48, 57.56, 55.73, 47.55, 46.15, 42.84, 42.45, 41.90, 41.60, 39.78, 38.71, 38.52, 36.93, 35.88, 
$33.94,33.15,32.53,31.94,31.60,31.48,30.88,29.73,29.68,29.65,29.63,29.29,29.19,28.25,27.48$, 26.00, 25.54, 23.92, 22.71, 18.21, 16.72, 16.34, 15.49, 14.14; HRMS: Molecular Formula: $\mathrm{C}_{44} \mathrm{H}_{76} \mathrm{O}_{3}$; Exact Mass: 652.57945; $\mathrm{m} / \mathrm{z}$ Calculated [M+1]+: 653.58727; Experimental: $\mathrm{m} / \mathrm{z}[\mathrm{M}+1]^{+}$: 653.58984

Compound 5c: m.p.: $194{ }^{\circ} \mathrm{C}$; White solid, $1.40 \mathrm{~g}, 88 \%$ yield, ${ }^{1} \mathrm{H}$ NMR $\left(500 \mathrm{MHz}, \mathrm{CDCl}_{3}\right) \delta 5.13(\mathrm{t}, J$ $=3.7 \mathrm{~Hz}, 1 \mathrm{H}), 3.94(\mathrm{~d}, J=11.0 \mathrm{~Hz}, 1 \mathrm{H}), 3.65(\mathrm{~d}, J=11.0 \mathrm{~Hz}, 1 \mathrm{H}), 3.28(\mathrm{~s}, 3 \mathrm{H}), 2.59(\mathrm{dd}, J=11.7,4.3$ $\mathrm{Hz}, 1 \mathrm{H}), 2.23(\mathrm{t}, J=7.4 \mathrm{~Hz}, 2 \mathrm{H}), 1.99(\mathrm{dd}, J=13.6,4.8 \mathrm{~Hz}, 1 \mathrm{H}), 1.92-1.27$ (multiple peak group of aliphatic region, 20H), 1.20-1.16 (m, fatty acid side chain, 32H), $1.09(\mathrm{~s}, 3 \mathrm{H}), 0.91(\mathrm{~s}, 3 \mathrm{H}), 0.88(\mathrm{~s}, 3 \mathrm{H})$, $0.86(\mathrm{~s}, 3 \mathrm{H}), 0.82(\mathrm{~s}, 3 \mathrm{H}), 0.81(\mathrm{t}, J=6.9 \mathrm{~Hz}, 3 \mathrm{H}), 0.80(\mathrm{~s}, 3 \mathrm{H}), 0.70(\mathrm{~s}, 3 \mathrm{H}) ;{ }^{13} \mathrm{C}$ NMR $(125 \mathrm{MHz}$, $\left.\mathrm{CDCl}_{3}\right) \delta 173.99,143.63,122.91,88.65,70.49,57.52,55.75,47.59,46.26,42.49,41.61,39.79,38.71$, 38.52 , 36.93, 35.84, 34.54, 34.02, 33.18, 32.55, 31.95, 31.46, 30.90, 29.74, 29.72, 29.55, 29.39, 29.32, 29.19, 28.11, 25.98, 25.57, 25.17, 23.60, 23.55, 22.71, 22.34, 22.02, 18.22, 16.71, 16.35, 15.49, 14.15; HRMS: Molecular Formula: $\mathrm{C}_{49} \mathrm{H}_{86} \mathrm{O}_{3}$; Exact Mass: 722.65770; Calculated $\mathrm{m} / \mathrm{z}[\mathrm{M}+1]^{+}$: 723.66552; Experimental: $m / z[\mathrm{M}+1]^{+}: 723.66785$

Compound 5d: m.p.: 192-194 ${ }^{\circ} \mathrm{C}$; White solid, $1.27 \mathrm{~g}, 78 \%$ yield; ${ }^{1} \mathrm{H}$ NMR $\left(500 \mathrm{MHz}, \mathrm{CDCl}_{3}\right) \delta 5.20$ $(\mathrm{t}, J=3.6 \mathrm{~Hz}, 1 \mathrm{H}), 4.02(\mathrm{~d}, J=11.0 \mathrm{~Hz}, 1 \mathrm{H}), 3.71(\mathrm{~d}, J=11.0 \mathrm{~Hz}, 1 \mathrm{H}), 3.35(\mathrm{~s}, 3 \mathrm{H}), 2.66(\mathrm{dd}, J=11.7$, $4.3 \mathrm{~Hz}, 1 \mathrm{H}), 2.30(\mathrm{t}, J=7.4 \mathrm{~Hz}, 2 \mathrm{H}), 2.06(\mathrm{dd}, J=13.6,4.8 \mathrm{~Hz}, 1 \mathrm{H}), 1.98-1.35$ (multiple peak group of aliphatic region, $20 \mathrm{H}), 1.29-1.22(\mathrm{~m}$, fatty acid side chain, $34 \mathrm{H}), 1.16(\mathrm{~s}, 3 \mathrm{H}), 0.98(\mathrm{~s}, 3 \mathrm{H}), 0.95(\mathrm{~s}$, $3 \mathrm{H}), 0.93(\mathrm{~s}, 3 \mathrm{H}), 0.89(\mathrm{~s}, 3 \mathrm{H}), 0.88(\mathrm{~s}, 3 \mathrm{H}), 0.81(\mathrm{t}, J=6.9 \mathrm{~Hz}, 3 \mathrm{H}), 0.77(\mathrm{~s}, 3 \mathrm{H}) ;{ }^{13} \mathrm{C} \mathrm{NMR}(125 \mathrm{MHz}$, $\left.\mathrm{CDCl}_{3}\right) \delta 173.78,143.61,122.89,88.58,70.42,60.05,57.44,55.76,47.60,46.26,42.49,41.58,39.78$, $38.69,38.52$, 36.92, 35.83, 34.48, 34.35, 34.03, 33.18, 32.54, 31.96, 31.47, 30.87, 29.75, 29.40, 28.10, 25.97, 25.56, 25.16, 24.98, 23.59, 23.54, 22.71, 22.32, 18.22, 16.68, 16.34, 15.48, 14.14; HRMS: fragments: $m / z:[\mathrm{M}+1]^{+}: 457.40336,299.25745$

Compound 5e: m.p.: $206{ }^{\circ} \mathrm{C}$; White solid, $1.15 \mathrm{~g}, 65 \%$ yield; ${ }^{1} \mathrm{H}$ NMR $\left(500 \mathrm{MHz}, \mathrm{CDCl}_{3}\right) \delta 5.13(\mathrm{t}, J$ $=3.6 \mathrm{~Hz}, 1 \mathrm{H}), 3.94(\mathrm{~d}, J=11.0 \mathrm{~Hz}, 1 \mathrm{H}), 3.64(\mathrm{~d}, J=11.0 \mathrm{~Hz}, 1 \mathrm{H}), 3.28(\mathrm{~s}, 3 \mathrm{H}), 2.59(\mathrm{dd}, J=11.7,4.3$ $\mathrm{Hz}, 1 \mathrm{H}), 2.23(\mathrm{t}, J=7.4 \mathrm{~Hz}, 2 \mathrm{H}), 1.99(\mathrm{dd}, J=13.6,4.6 \mathrm{~Hz}, 1 \mathrm{H}), 1.91-1.26$ (multiple peak group of aliphatic region, 22H), 1.20-1.17 (m, fatty acid side chain, 42H), $1.09(\mathrm{~s}, 3 \mathrm{H}), 0.91(\mathrm{~s}, 3 \mathrm{H}), 0.88(\mathrm{~s}, 3 \mathrm{H})$, $0.86(\mathrm{~s}, 3 \mathrm{H}), 0.82(\mathrm{~s}, 3 \mathrm{H}), 0.81(\mathrm{t}, J=6.9 \mathrm{~Hz}, 3 \mathrm{H}), 0.80(\mathrm{~s}, 3 \mathrm{H}), 0.70(\mathrm{~s}, 3 \mathrm{H}) .{ }^{13} \mathrm{C}$ NMR $(125 \mathrm{MHz}$, $\left.\mathrm{CDCl}_{3}\right) \delta 173.93,143.63,122.91,88.63,70.95,70.46,57.52,55.76,47.60,46.26,42.49,41.95,41.61$, $39.80,38.71,38.53,36.93,35.85,34.53,34.03,33.19,32.56,31.96,31.47,30.90,29.75,29.70,29.65$, $29.57,29.41,29.33,29.19,28.12,25.99,25.57,25.18,23.60,23.56,22.72,22.34,22.02,18.22,16.71$, 16.36, 15.50, 14.16; HRMS: fragments: $m / z:[\mathrm{M}+1]^{+}: 457.40336,369.35168$

Compound 5f: m.p.: $208^{\circ} \mathrm{C}$; White solid, $1.20 \mathrm{~g}, 66 \%$ yield; ${ }^{1} \mathrm{H}$ NMR $\left(500 \mathrm{MHz}, \mathrm{CDCl}_{3}\right) \delta 5.20(\mathrm{t}, J=$ $3.6 \mathrm{~Hz}, 1 \mathrm{H}), 4.01(\mathrm{~d}, J=11.0 \mathrm{~Hz}, 1 \mathrm{H}), 3.71(\mathrm{~d}, J=11.0 \mathrm{~Hz}, 1 \mathrm{H}), 3.35(\mathrm{~s}, 3 \mathrm{H}), 2.66(\mathrm{dd}, J=11.6,4.3$ $\mathrm{Hz}, 1 \mathrm{H}), 2.30(\mathrm{t}, J=7.4 \mathrm{~Hz}, 2 \mathrm{H}), 2.06(\mathrm{dd}, J=13.6,4.6 \mathrm{~Hz}, 1 \mathrm{H}), 1.97-1.35$ (multiple peak group of aliphatic region, 22H), $1.35-1.21(\mathrm{~m}$, fatty acid side chain, $44 \mathrm{H}), 1.16(\mathrm{~s}, 3 \mathrm{H}), 0.98(\mathrm{~s}, 3 \mathrm{H}), 0.95(\mathrm{~s}$, $3 \mathrm{H}), 0.93(\mathrm{~s}, 3 \mathrm{H}), 0.89(\mathrm{~s}, 6 \mathrm{H}), 0.81(\mathrm{t}, J=6.9 \mathrm{~Hz}, 3 \mathrm{H}), 0.77(\mathrm{~s}, 3 \mathrm{H}) ;{ }^{13} \mathrm{C} \mathrm{NMR}\left(125 \mathrm{MHz}, \mathrm{CDCl}_{3}\right) \delta$; $173.95,143.61,122.81,88.67,70.91,70.45,57.50,55.70,47.61,46.20,42.45,41.91,41.65,39.82$, $38.77,38.55,36.92,35.87,34.57,34.04,33.18,32.57,31.98,31.48,30.92$, 29.75, 29.70, 29.65, 29.57, $29.41,29.33,29.19,28.12,25.99,25.57,25.18,23.61,23.52,22.71,22.37,22.02,18.22,16.76,16.36$, 15.50, 14.19; HRMS: Molecular Formula: $\mathrm{C}_{56} \mathrm{H}_{100} \mathrm{O}_{3}$; Exact Mass: 820.76725; Calculated $\mathrm{m} / \mathrm{z}$ $[\mathrm{M}+1]^{+}:$821.77507; Experimental: $\mathrm{m} / z[\mathrm{M}+1]^{+}: 821.77257$

Compound 8a: m.p.: $185^{\circ} \mathrm{C}$; White solid, $1.10 \mathrm{~g}, 79 \%$ yield; ${ }^{1} \mathrm{H}$ NMR $\left(500 \mathrm{MHz}, \mathrm{CDCl}_{3}\right) \delta 5.14$ (t, $J=$ $3.7 \mathrm{~Hz}, 1 \mathrm{H}), 4.06(\mathrm{~d}, J=11.0 \mathrm{~Hz}, 1 \mathrm{H}), 3.62(\mathrm{~d}, J=11.0 \mathrm{~Hz}, 1 \mathrm{H}), 3.35(\mathrm{~s}, 3 \mathrm{H}), 2.66(\mathrm{dd}, J=11.7,4.3$ $\mathrm{Hz}, 1 \mathrm{H}), 2.29(\mathrm{t}, J=7.5 \mathrm{~Hz}, 2 \mathrm{H}), 2.04-1.33$ (multiple peak group of aliphatic region, $23 \mathrm{H}$ ), $1.28-1.25$ $(\mathrm{m}$, yağ asiti yan zinciri, $18 \mathrm{H}), 1.10(\mathrm{~s}, 3 \mathrm{H}), 0.99(\mathrm{~s}, 3 \mathrm{H}), 0.98(\mathrm{~s}, 3 \mathrm{H}), 0.94(\mathrm{~s}, 3 \mathrm{H}), 0.93(\mathrm{~s}, 3 \mathrm{H}), 0.88$ $(\mathrm{t}, J=6.9 \mathrm{~Hz}, 3 \mathrm{H}), 0.82(\mathrm{~d}, J=4.9 \mathrm{~Hz}, 3 \mathrm{H}), 0.77(\mathrm{~s}, 3 \mathrm{H}) ;{ }^{13} \mathrm{C} \mathrm{NMR}\left(125 \mathrm{MHz}, \mathrm{CDCl}_{3}\right) \delta 173.87,138.15$, $125.65,88.63$, 70.92, 57.49, 55.75, 54.34, 47.68, 41.93, 39.99, 39.36, 39.24, 38.69, 36.91, 36.87, 35.79, $34.48,32.80,31.95,30.56,29.67,29.65,29.58,29.38,29.33,29.18,28.14,26.03,25.18,23.44,23.35$, 
22.72, 22.05, 21.30, 18.19, 17.32, 16.73, 16.38, 15.65, 14.15; HRMS: Molecular Formula: $\mathrm{C}_{43} \mathrm{H}_{74} \mathrm{O}_{3}$; Exact Mass: 638.56380; Calculated $\mathrm{m} / \mathrm{z}[\mathrm{M}+1]^{+}:$639.57162; Experimental: $\mathrm{m} / \mathrm{z}[\mathrm{M}+1]^{+}$: 639.57086

Compound $8 \boldsymbol{b}$ : m.p.: $184{ }^{\circ} \mathrm{C}$; White solid, $1.16 \mathrm{~g}, 82 \%$ yield; ${ }^{1} \mathrm{H}$ NMR $\left(500 \mathrm{MHz}, \mathrm{CDCl}_{3}\right) \delta 5.14(\mathrm{t}, J$ $=3.7 \mathrm{~Hz}, 1 \mathrm{H}), 4.06(\mathrm{~d}, J=11.0 \mathrm{~Hz}, 1 \mathrm{H}), 3.62(\mathrm{~d}, J=11.0 \mathrm{~Hz}, 1 \mathrm{H}), 3.35(\mathrm{~s}, 3 \mathrm{H}), 2.66(\mathrm{dd}, J=11.6,4.3$ $\mathrm{Hz}, 1 \mathrm{H}), 2.29(\mathrm{t}, J=7.4 \mathrm{~Hz}, 2 \mathrm{H}), 2.02-1.34$ (multiple peak group of aliphatic region, $23 \mathrm{H}$ ), $1.32-1.22$ (m, fatty acid side chain, 20H), $1.10(\mathrm{~s}, 3 \mathrm{H}), 0.99(\mathrm{~s}, 3 \mathrm{H}), 0.98(\mathrm{~s}, 3 \mathrm{H}), 0.94(\mathrm{~s}, 3 \mathrm{H}), 0.93(\mathrm{~s}, 3 \mathrm{H}), 0.88$ $(\mathrm{t}, J=6.9 \mathrm{~Hz}, 3 \mathrm{H}), 0.82(\mathrm{~d}, J=5.0 \mathrm{~Hz}, 3 \mathrm{H}), 0.77(\mathrm{~s}, 3 \mathrm{H}) ;{ }^{13} \mathrm{C} \mathrm{NMR}\left(125 \mathrm{MHz}, \mathrm{CDCl}_{3}\right) \delta 173.75,138.15$, $125.63,88.58,70.88,57.43,55.75,54.35,47.68,41.92$, 39.98, 39.97, 39.36, 39.23, 38.71, 38.67, 36.90, $36.85,35.79,34.44,32.79,31.95,31.93,30.56,29.72$, 29.51, 29.48, 28.13, 26.03, 25.16, 23.44, 23.42, 23.34, 22.71, 22.02, 21.29, 18.19, 17.31, 16.71, 16.37, 15.64, 14.14; HRMS: Molecular Formula: $\mathrm{C}_{44} \mathrm{H}_{76} \mathrm{O}_{3}$; Exact Mass: 652.57945; Calculated $\mathrm{m} / \mathrm{z}[\mathrm{M}+1]^{+}:$653.58727; Experimental: $\mathrm{m} / \mathrm{z}$ $[\mathrm{M}+1]^{+}: 653.58563$

Compound 8c: m.p.: $196^{\circ} \mathrm{C}$; White solid, $1.48 \mathrm{~g}, 93 \%$ yield; ${ }^{1} \mathrm{H}$ NMR $\left(500 \mathrm{MHz}, \mathrm{CDCl}_{3}\right) \delta 5.07$ (t, $J=$ $3.7 \mathrm{~Hz}, 1 \mathrm{H}), 3.99(\mathrm{~d}, J=11.0 \mathrm{~Hz}, 1 \mathrm{H}), 3.55(\mathrm{~d}, J=11.0 \mathrm{~Hz}, 1 \mathrm{H}), 3.28(\mathrm{~s}, 3 \mathrm{H}), 2.59(\mathrm{dd}, J=11.7,4.3$ $\mathrm{Hz}, 1 \mathrm{H}), 2.21(\mathrm{t}, J=7.5 \mathrm{~Hz}, 2 \mathrm{H}), 1.93-1.26$ (multiple peak group of aliphatic region, $24 \mathrm{H}$ ), $1.22-1.15$ (m, fatty acid side chain, 30H), $1.03(\mathrm{~s}, 3 \mathrm{H}), 0.92(\mathrm{~s}, 3 \mathrm{H}), 0.91(\mathrm{~s}, 3 \mathrm{H}), 0.88(\mathrm{~s}, 3 \mathrm{H}), 0.86(\mathrm{~s}, 3 \mathrm{H}), 0.81$ $(\mathrm{t}, J=13.3 \mathrm{~Hz}, 3 \mathrm{H}), 0.75(\mathrm{~d}, J=5.3 \mathrm{~Hz}, 3 \mathrm{H}), 0.70(\mathrm{~s}, 3 \mathrm{H}) ;{ }^{13} \mathrm{C} \mathrm{NMR}\left(126 \mathrm{MHz}, \mathrm{CDCl}_{3}\right) \delta 173.73$, $138.14,125.62,88.57,70.88,57.41,55.76,54.35,47.68,41.91,39.98,39.36,39.23,38.70,38.67,36.90$, $36.85,35.79,34.43,32.79,31.95,30.56,29.76,29.73,29.71,29.65,29.58,29.40,29.17,28.12$, 26.02, 25.16, 23.43, 23.34, 22.71, 22.02, 21.28, 18.19, 17.30, 16.71, 16.36, 15.64, 14.14; HRMS: Molecular Formula: $\mathrm{C}_{49} \mathrm{H}_{86} \mathrm{O}_{3}$; Exact Mass: 722.65770; Calculated $m / z[\mathrm{M}+1]^{+}:$723.66552; Experimental: $[\mathrm{M}+1]^{+}: 723.66786$

Compound 8d: m.p.: $197^{\circ} \mathrm{C}$; White solid, $1.33 \mathrm{~g}, 82 \%$ yield; ${ }^{1} \mathrm{H}$ NMR $\left(500 \mathrm{MHz}, \mathrm{CDCl}_{3}\right) \delta 5.14(\mathrm{~d}, J$ $=3.7 \mathrm{~Hz}, 1 \mathrm{H}), 4.06(\mathrm{~d}, J=11.0 \mathrm{~Hz}, 1 \mathrm{H}), 3.62(\mathrm{~d}, J=11.0 \mathrm{~Hz}, 1 \mathrm{H}), 3.35(\mathrm{~s}, 3 \mathrm{H}), 2.66(\mathrm{dd}, J=11.6,4.3$ $\mathrm{Hz}, 1 \mathrm{H}), 2.29(\mathrm{t}, J=7.4 \mathrm{~Hz}, 2 \mathrm{H}), 2.01-1.34$ (multiple peak group of aliphatic region, $23 \mathrm{H}$ ), $1.28-1.25$ (m, fatty acid side chain, 32H), $1.10(\mathrm{~s}, 3 \mathrm{H}), 0.99(\mathrm{~s}, 3 \mathrm{H}), 0.98(\mathrm{~s}, 3 \mathrm{H}), 0.94(\mathrm{~s}, 3 \mathrm{H}), 0.93(\mathrm{~s}, 3 \mathrm{H}), 0.88$ (t, $J=6.9 \mathrm{~Hz}, 3 \mathrm{H}), 0.82(\mathrm{~d}, J=4.8 \mathrm{~Hz}, 3 \mathrm{H}), 0.77(\mathrm{~s}, 3 \mathrm{H}) ;{ }^{13} \mathrm{C} \mathrm{NMR}\left(125 \mathrm{MHz}, \mathrm{CDCl}_{3}\right) \delta 173.87,138.15$, $125.65,88.63,70.93,57.46,55.76,54.35,47.69,41.94,40.00,39.37,39.24,38.69,36.92,36.87,35.79$, $34.47,32.80,31.96,30.56,29.75,29.70,29.58,29.40,29.33,29.18,28.13,26.03,25.17,23.43,23.35$, $22.71,22.04,21.29,18.19,17.31,16.73,16.37,15.65,14.14$; HRMS: fragments: $m / z$ : $[\mathrm{M}+1]^{+}$: 457.40336, 299.29398

Compound $8 \boldsymbol{e}$ : m.p.: $208^{\circ} \mathrm{C}$; White solid, $1.24 \mathrm{~g}, 70 \%$ yield; ${ }^{1} \mathrm{H}$ NMR $\left(500 \mathrm{MHz}, \mathrm{CDCl}_{3}\right) \delta 5.10(\mathrm{t}, J$ $=3.7 \mathrm{~Hz}, 1 \mathrm{H}), 4.01(\mathrm{~d}, J=11.0 \mathrm{~Hz}, 1 \mathrm{H}), 3.58(\mathrm{~d}, J=11.1 \mathrm{~Hz}, 1 \mathrm{H}), 3.31(\mathrm{~s}, 3 \mathrm{H}), 2.62(\mathrm{dd}, J=11.7,4.3$ $\mathrm{Hz}, 1 \mathrm{H}), 2.25(\mathrm{t}, J=7.4 \mathrm{~Hz}, 2 \mathrm{H}), 1.98-1.31$ (multiple peak group of aliphatic region, $23 \mathrm{H}$ ), $1.28-1.11$ (m, fatty acid side chain, 42H), $1.05(\mathrm{~s}, 3 \mathrm{H}), 0.95(\mathrm{~s}, 3 \mathrm{H}), 0.93(\mathrm{~s}, 3 \mathrm{H}), 0.90(\mathrm{~s}, 3 \mathrm{H}), 0.89(\mathrm{~s}, 3 \mathrm{H}), 0.84$ $(\mathrm{t}, J=6.9 \mathrm{~Hz}, 3 \mathrm{H}), 0.77(\mathrm{~d}, J=5.4 \mathrm{~Hz}, 3 \mathrm{H}), 0.73(\mathrm{~s}, 3 \mathrm{H}) ;{ }^{13} \mathrm{C} \mathrm{NMR}\left(125 \mathrm{MHz}, \mathrm{CDCl}_{3}\right) \delta 173.96,138.15$, $125.67,88.68,70.96,57.52,55.77,54.35,47.69,41.95,40.01,39.37,39.25,38.71,36.93,36.88,35.79$, $34.51,32.81,31.96,30.57,29.75,29.71,29.66,29.59,29.41,29.34,29.19,28.15,26.04,25.19,23.45$, 23.36, 22.73, 22.07, 21.31, 18.20, 17.33, 16.75, 16.39, 15.67, 14.16; HRMS: fragments: $m / z:[\mathrm{M}+1]^{+}$: $457.40336,369.37305$

Compound 8f: m.p.: $209^{\circ} \mathrm{C}$; White solid, $1.3 \mathrm{~g}, 72 \%$ yield; ${ }^{1} \mathrm{H}$ NMR $\left(500 \mathrm{MHz}, \mathrm{CDCl}_{3}\right) \delta 5.07(\mathrm{t}, J=$ $3.6 \mathrm{~Hz}, 1 \mathrm{H}), 3.98(\mathrm{~d}, J=11.0 \mathrm{~Hz}, 1 \mathrm{H}), 3.56(\mathrm{~d}, J=11.0 \mathrm{~Hz}, 1 \mathrm{H}), 3.29(\mathrm{~s}, 3 \mathrm{H}), 2.60(\mathrm{dd}, J=11.7,4.3$ $\mathrm{Hz}, 1 \mathrm{H}), 2.22(\mathrm{t}, J=7.4 \mathrm{~Hz}, 2 \mathrm{H}), 1.96-1.28$ (multiple peak group of aliphatic region, $23 \mathrm{H}$ ), 1.18 (s, fatty acid side chain, 44H), $1.03(\mathrm{~s}, 3 \mathrm{H}), 0.92(\mathrm{~s}, 3 \mathrm{H}), 0.91(\mathrm{~s}, 3 \mathrm{H}), 0.87(\mathrm{~d}, J=4.8 \mathrm{~Hz}, 3 \mathrm{H}), 0.81(\mathrm{~s}$, $3 \mathrm{H}), 0.81(\mathrm{t}, J=6.9 \mathrm{~Hz}, 3 \mathrm{H}), 0.75(\mathrm{~d}, J=5.2 \mathrm{~Hz}, 3 \mathrm{H}), 0.70(\mathrm{~s}, 3 \mathrm{H}) ;{ }^{13} \mathrm{C} \mathrm{NMR}\left(125 \mathrm{MHz}, \mathrm{CDCl}_{3}\right) \delta$ 174.03, 138.15, 125.68, 88.70, 70.97, 69.95, 57.57, 55.76, 54.34, 47.68, 44.18, 41.97, 40.01, 39.37, $39.25,38.72,36.93,36.89,35.79,34.54,32.81,31.95,30.56,29.73,29.69,29.66,29.58,29.39,29.33$, $29.19,28.98,28.92,28.60,28.15,26.47,26.04,25.72,25.19,23.46,23.36,22.72,22.08,21.31,18.20$, 
17.33, 16.76, 16.39, 15.67, 14.15; HRMS: Molecular Formula: $\mathrm{C}_{56} \mathrm{H}_{100} \mathrm{O}_{3}$; Exact Mass: 820.76725; Calculated $\mathrm{m} / z[\mathrm{M}+1]^{+}: 821.77507$; Experimental: $\mathrm{m} / z$ [M+1] $]^{+}: 821.77167$

\section{Results and Discussion}

\subsection{Syntheses}

In this study, 12 new oleanane and ursane derivative triterpene compounds, having fatty acids in the form of esters with carbon numbers of $12,13,18,19,24$ and 25 , were synthesized starting from natural products oleanolic and ursolic acids. Initially, 3-methylerythrodiol(3 $\beta$-methoxyolean-12-en-28-ol) (3) and 3-methyluvaol (3 $\beta$-methoxyurs-12-en-28-ol) (6) were synthesized from oleanolic and ursolic acids, respectively (Schemes 1 and 2). For this purpose, secondary $\mathrm{OH}$ at C-3 and the acid groups of oleanolic and ursolic acids were protected as methyl ethers and esters $(\mathbf{3}$ and $\mathbf{6})$ then, the ester moieties were reduced with aluminum hydride to produce $\mathbf{4}$ and $\mathbf{7}$. New triterpene-fatty acid derivatives 5a-f and 8a-f were synthesized from reactions of 3-methylerythrodiol and 3-methyluvaol with corresponding fatty acid halides.
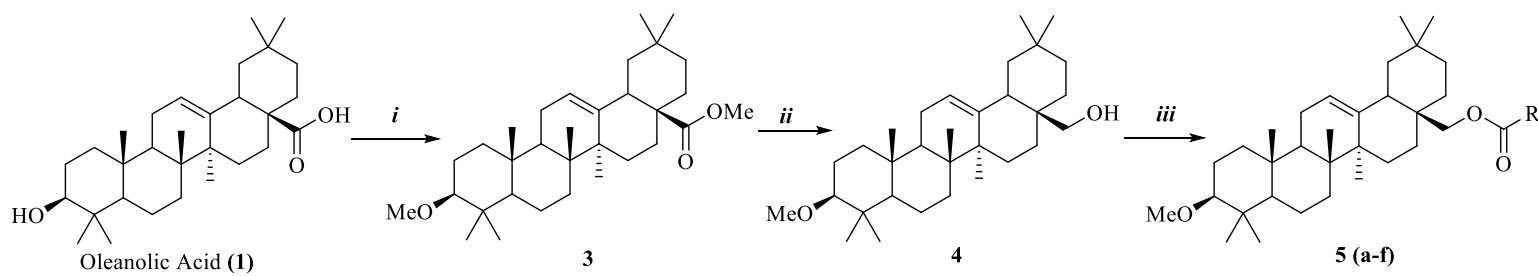

$$
\begin{aligned}
& \text { 5a: } \mathrm{R}=\mathrm{C}_{11} \mathrm{H}_{23}-\text { Laurat derivative, } 86 \% \\
& \text { 5b: } \mathrm{R}=\mathrm{C}_{12} \mathrm{H}_{25} \text { - Tridecylat derivative, } 82 \% \\
& \text { 5c: } \mathrm{R}=\mathrm{C}_{17} \mathrm{H}_{35}-\text { Stearat derivative, } 88 \% \\
& \text { 5d: } \mathrm{R}=\mathrm{C}_{18} \mathrm{H}_{37} \text { - Nonadecanoat derivative, } 78 \% \\
& \text { 5e: } \mathrm{R}=\mathrm{C}_{23} \mathrm{H}_{47}-\text { Lignocerat derivative, } 65 \% \\
& \text { 5f: } \mathrm{R}=\mathrm{C}_{24} \mathrm{H}_{49}-\text { Pentacosanoat derivative, } 66 \%
\end{aligned}
$$

Scheme 1. Syntheses of oleanane triterpenoids having fatty acid esters

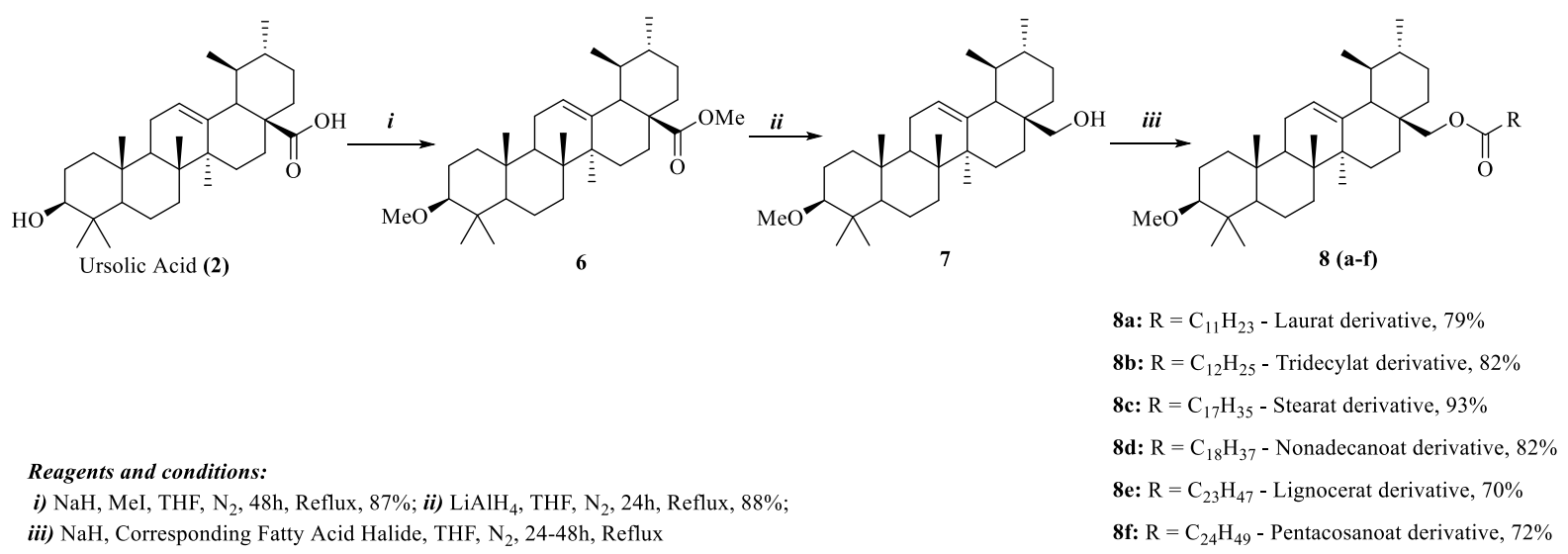

Scheme 2. Syntheses of ursane triterpenoids having fatty acid esters

In the NMR analysis of the compounds, the chemical shift values of the hydrogens and carbons belong to the $\mathrm{C}-28$ position are given comparatively in Table 1 for ursane and oleanane derivatives. The chemical shift values differed $\pm 0.1 \mathrm{ppm}$ depending on the length of the fatty acid. Due to the increasing carbon number, a marked decrease in the polarities of the compounds were observed. For this reason, the most suitable solvent for all the compounds were found to be chloroform and THF. 
Table 1. Chemical shift values of carbons and hydrogens at the 28 position of the synthesized compounds

\begin{tabular}{|c|c|c|c|c|c|c|c|}
\hline \multicolumn{4}{|c|}{ Oleanane derivatives } & \multicolumn{4}{|c|}{ Ursane derivatives } \\
\hline Comp. & ${ }^{1} \mathbf{H}-\mathbf{N I}$ & $\delta$ ppm & ${ }^{13} \mathrm{C}$-NMR $\delta$ ppm & Comp. & ${ }^{1} \mathrm{H}-\mathrm{N}$ & $\delta \mathrm{ppm}$ & ${ }^{13} \mathrm{C}-\mathrm{NMR} \delta \mathrm{ppm}$ \\
\hline 4 & 3.53 & 3.18 & 69.63 & 7 & 3.52 & 3.35 & 69.90 \\
\hline $5 \mathbf{a}$ & 3.94 & 3.64 & 70.47 & $\mathbf{8 a}$ & 4.06 & 3.62 & 70.92 \\
\hline $5 \mathbf{b}$ & 4.02 & 3.72 & 71.56 & $8 \mathbf{b}$ & 4.06 & 3.62 & 70.88 \\
\hline $5 c$ & 3.94 & 3.65 & 70.49 & $8 c$ & 3.99 & 3.55 & 70.88 \\
\hline 5d & 4.02 & 3.71 & 70.42 & 8d & 4.06 & 3.62 & 70.93 \\
\hline $5 e$ & 3.94 & 3.64 & 70.95 & $8 \mathbf{e}$ & 4.01 & 3.58 & 70.96 \\
\hline $5 f$ & 4.01 & 3.71 & 70.96 & $8 f$ & 3.98 & 3.56 & 70.97 \\
\hline
\end{tabular}

\subsection{Biological Activity Studies}

All the synthesized compounds were investigated for their cytotoxic effects against 3T3 fibroblast human healthy and PC3 prostate cancer cell lines. The cytotoxic effects and $\mathrm{IC}_{50}$ values of the compounds on $3 \mathrm{~T} 3$ fibroblast human health cells are given in Table 2 and the cytotoxic effects and $\mathrm{IC}_{50}$ values on PC3 prostate cancer cells are given in Table 3. The graphics of the results in Tables 2 and 3 are given in Figures 1 and 2, respectively.

Table 2. Cytotoxic effects of compounds on $3 \mathrm{~T} 3$ fibroblast human healthy cells

\begin{tabular}{cccccccc}
\hline Concentration & $100 \mu \mathrm{M}$ & $50 \mu \mathrm{M}$ & $25 \mu \mathrm{M}$ & $12.5 \mu \mathrm{M}$ & $6.25 \mu \mathrm{M}$ & $3.125 \mu \mathrm{M}$ & $\mathrm{IC}_{50} \mu \mathrm{M}$ \\
\hline Control & 100 & 100 & 100 & 100 & 100 & 100 & \\
\hline $\mathbf{1}$ & 25.1232 & 57.0334 & 76.7378 & 97.0991 & 130.5966 & 117.4603 & $75.74 \pm 0.2283$ \\
$\mathbf{2}$ & 39.2308 & 76.4103 & 79.4872 & 91.0256 & 81.0256 & 86.4103 & $89.81 \pm 0.1072$ \\
$\mathbf{3}$ & 49.1516 & 67.5424 & 89.8741 & 118.7739 & 149.6442 & 135.1943 & $64.30 \pm 0.4286$ \\
$\mathbf{4}$ & 21.8391 & 31.0345 & 46.7980 & 65.8457 & 83.5796 & 94.0887 & $25.05 \pm 0.0322$ \\
$\mathbf{6}$ & 61.0256 & 71.0256 & 76.4103 & 82.5641 & 108.7179 & 131.7949 & $135.40 \pm 0.2145$ \\
$\mathbf{7}$ & 23.0769 & 35.3846 & 36.9231 & 39.2308 & 78.4615 & 100.0000 & $17.38 \pm 0.1149$ \\
$\mathbf{5 a}$ & 17.2932 & 24.3108 & 24.8120 & 32.3308 & 31.3283 & 32.8321 & $3.11 \pm 0.1700$ \\
$\mathbf{5 b}$ & 21.3033 & 32.8321 & 36.8421 & 62.4060 & 82.9574 & 61.4035 & $18.16 \pm 0.1137$ \\
$\mathbf{5 c}$ & 23.1527 & 46.1412 & 70.4434 & 106.5681 & 125.6158 & 151.8883 & $68.88 \pm 0.3337$ \\
$\mathbf{5 d}$ & 33.5692 & 41.8121 & 48.8081 & 53.3343 & 68.2011 & 75.6610 & $22.52 \pm 0.0912$ \\
$\mathbf{5 e}$ & 23.8095 & 54.1353 & 68.6717 & 92.2306 & 114.7870 & 91.2281 & $58.89 \pm 0.1322$ \\
$\mathbf{5 f}$ & 42.1053 & 48.1203 & 51.6291 & 54.1353 & 58.1454 & 58.6466 & $21.59 \pm 0.1930$ \\
$\mathbf{8 a}$ & 10.8861 & 20.5063 & 25.0633 & 36.2025 & 51.8987 & 64.5570 & $7.26 \pm 0.0470$ \\
$\mathbf{8 b}$ & 14.4304 & 22.5317 & 22.0253 & 32.1519 & 79.7468 & 80.2532 & $10.87 \pm 0.1016$ \\
$\mathbf{8 c}$ & 30.0000 & 40.7692 & 46.1539 & 56.1539 & 75.3846 & 83.0769 & $23.17 \pm 0.0755$ \\
$\mathbf{8 d}$ & 22.5769 & 37.1846 & 38.0231 & 40.2908 & 68.9615 & 80.5400 & $11.033 \pm 0.2567$ \\
$\mathbf{8 e}$ & 14.9367 & 47.9325 & 63.6287 & 71.2236 & 108.6920 & 105.6540 & $42.16 \pm 0.1283$ \\
$\mathbf{8 f}$ & 38.8186 & 49.9578 & 54.5148 & 64.1350 & 72.7426 & 90.9705 & $35.75 \pm 0.0934$ \\
\hline
\end{tabular}


Cytotoxic Effects of Compounds on 3T3 Fibroblast Human Healthy Cells

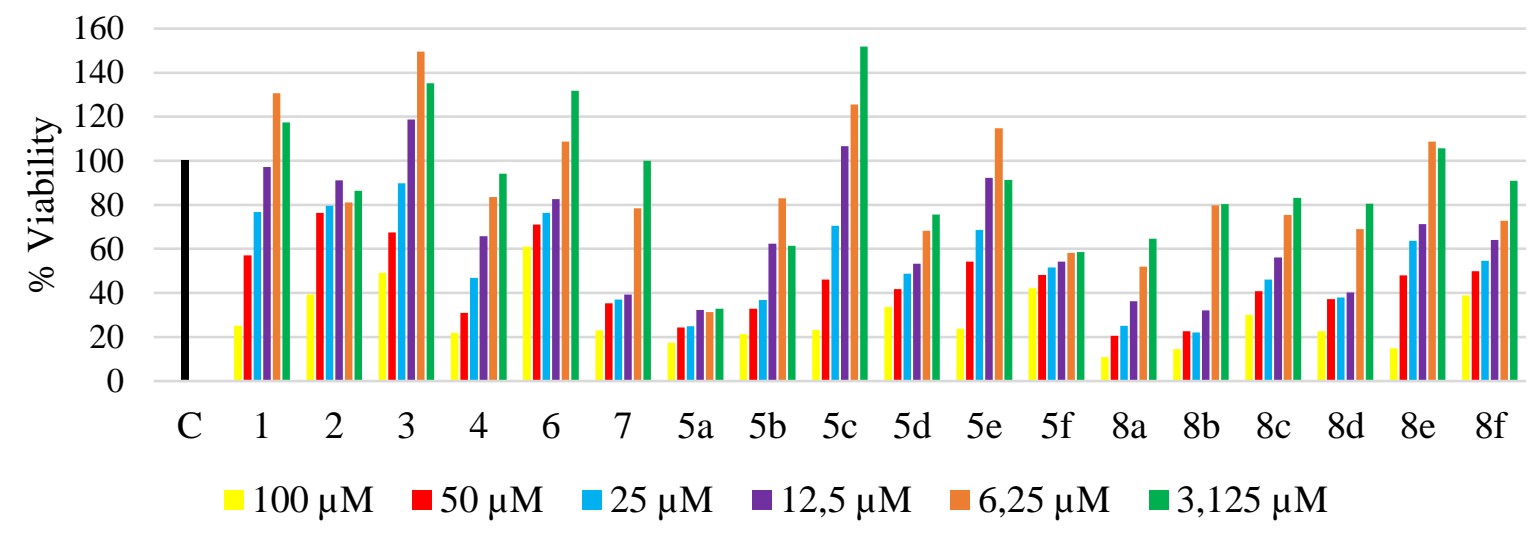

Figure 1. Cytotoxic effects of compounds on $3 \mathrm{~T} 3$ fibroblast human healthy cells (C: Control)

Table 3. Cytotoxic effects of compounds on PC3 prostate cancer cells

\begin{tabular}{cccccccc}
\hline Concentration & $100 \mu \mathrm{M}$ & $50 \mu \mathrm{M}$ & $25 \mu \mathrm{M}$ & $12.5 \mu \mathrm{M}$ & $6.25 \mu \mathrm{M}$ & $3.125 \mu \mathrm{M}$ & $\mathrm{IC} 50 \mu \mathrm{M}$ \\
\hline Control & 100 & 100 & 100 & 100 & 100 & 100 & \\
\hline Cisplatin & & & & & & & 399.35 \\
$\mathbf{1}$ & 5.5493 & 18.3843 & 50.6606 & 67.6482 & 109.5508 & 108.0785 & $26.40 \pm 0.1697$ \\
$\mathbf{2}$ & 7.7018 & 13.0212 & 13.2676 & 13.7605 & 18.3200 & 35.3255 & $1.77 \pm 0.0851$ \\
$\mathbf{3}$ & 20.9891 & 19.8566 & 59.9472 & 57.5689 & 69.0072 & 59.3809 & $17.39 \pm 0.1369$ \\
$\mathbf{4}$ & 5.3228 & 11.2118 & 38.8449 & 53.0011 & 83.3522 & 87.5425 & $15.14 \pm 0.0817$ \\
$\mathbf{6}$ & 10.9263 & 12.4050 & 14.7464 & 24.7279 & 57.1370 & 118.8745 & $9.52 \pm 0.2060$ \\
$\mathbf{7}$ & 4.7443 & 6.0998 & 6.3463 & 16.0813 & 32.8404 & 66.3586 & $3.692 \pm 0.0762$ \\
$\mathbf{5 a}$ & 48.6866 & 36.2408 & 7.6766 & 16.6539 & 35.2206 & 48.6866 & $3.712 \pm 0.2616$ \\
$\mathbf{5 b}$ & 4.9222 & 7.5746 & 13.7975 & 53.4813 & 77.7608 & 132.5427 & $14.63 \pm 0.2401$ \\
$\mathbf{5 c}$ & 15.6285 & 11.0985 & 28.6523 & 43.6014 & 58.7769 & 59.6829 & $8.26 \pm 0.0703$ \\
$\mathbf{5 d}$ & 4.5202 & 7.5998 & 20.9180 & 52.4813 & 76.7208 & 86.5325 & $21.93 \pm 0.046$ \\
$\mathbf{5 e}$ & 4.8202 & 14.1971 & 20.3180 & 51.5345 & 89.0759 & 119.3743 & $15.90 \pm 0.1879$ \\
$\mathbf{5 f}$ & 34.0899 & 29.9073 & 23.2764 & 25.2147 & 45.1075 & 61.3279 & $6.08 \pm 0.1562$ \\
$\mathbf{8 a}$ & 3.5081 & 7.4141 & 15.2260 & 47.4864 & 75.5515 & 122.5678 & $13.07 \pm 0.2055$ \\
$\mathbf{8 b}$ & 3.6528 & 5.2441 & 11.0307 & 32.4412 & 59.0597 & 105.0633 & $8.62 \pm 0.1575$ \\
$\mathbf{8 c}$ & 5.4837 & 7.2089 & 11.8916 & 28.5274 & 65.2495 & 85.3358 & $7.75 \pm 0.0995$ \\
$\mathbf{8 d}$ & 11.8263 & 14.4940 & 24.3364 & 44.9239 & 79.5370 & 98.4745 & $26.88 \pm 0.0312$ \\
$\mathbf{8 e}$ & 4.0868 & 13.7673 & 25.6299 & 60.3496 & 85.2321 & 131.6697 & $18.27 \pm 0.2183$ \\
$\mathbf{8 f}$ & 4.0000 & 14.3460 & 24.4726 & 52.3930 & 76.2628 & 131.5250 & $15.89 \pm 0.2168$ \\
\hline
\end{tabular}

Cytotoxic effects of compounds on PC3 prostate cancer cells

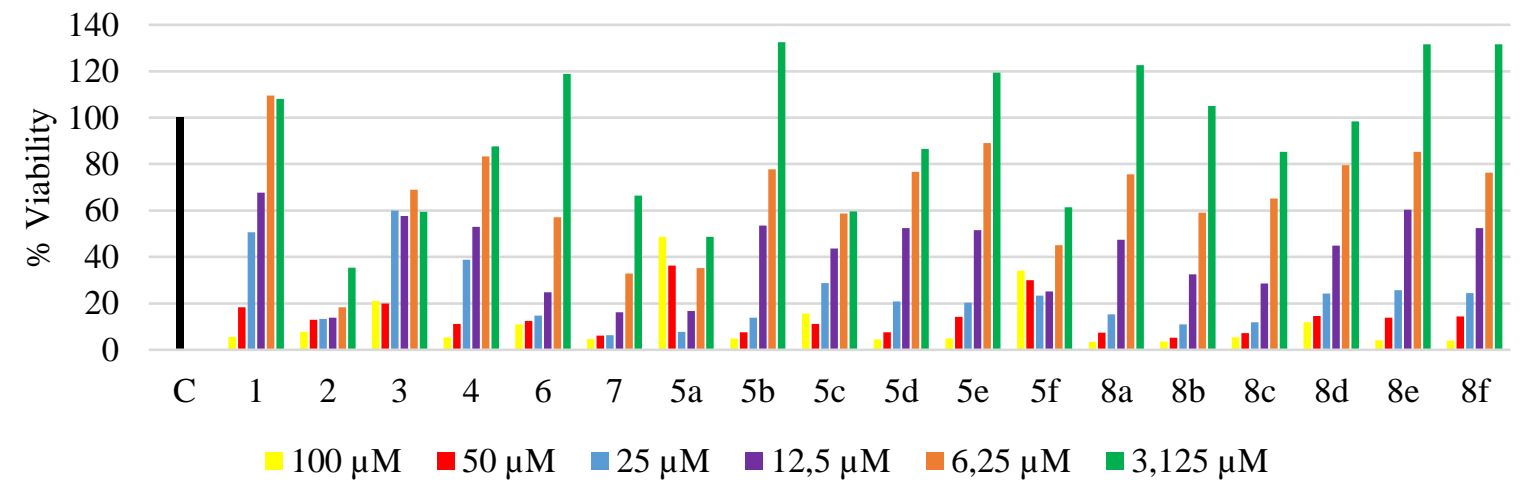

Figure 2. Cytotoxic effects of the compounds on PC3 prostate cancer cells

According to the results of the biological activities, the compounds exhibited cytotoxic effects on $3 \mathrm{~T} 3$ fibroblast human healthy cells on an average of $2 / 3$ of the cells at a concentration of $100 \mu \mathrm{M}$, 
and the cytotoxic effects decreased with decreasing doses. Compound 8a was observed to be the most toxic one against 3T3 fibroblast human healthy cells at a concentration of $100 \mu \mathrm{M}$, while the compound with the least toxic effect on 3T3 fibroblast human healthy cells was determined to be 5f. It was observed that 5c, 5e and 8e proliferated $3 \mathrm{~T} 3$ fibroblast human healthy cells at lower concentrations. The compound with the lowest toxicity at a concentration of $25 \mu \mathrm{M}$ on 3T3 fibroblast human healthy cells was $5 \mathbf{c}$.

According to the results of the cytotoxic effects of the compounds on PC3 prostate cancer cells, compound 5a was the most toxic at a concentration of $3.125 \mu \mathrm{M}$. Compound 5a killed approximately $52 \%$ of cancerous cells at a concentration of $3.125 \mu \mathrm{M}$, while the effects of other triterpene derivatives appeared to be weaker at this concentration. For TD50, the lowest average concentration that killed at least $50 \%$ of cancerous cells was $12.5 \mu \mathrm{M}$. These results revealed that the compounds had toxic effects on at least $50 \%$ of cancer cells at a concentration of $12.5 \mu \mathrm{M}$. At a concentration of $25 \mu \mathrm{M}$, all the compounds showed at least $70 \%$ toxicity on PC3 prostate cancer cells. These results added a great deal of value to the results of the experiments on healthy cells as the compounds showed less than $50 \%$ toxicity on healthy cells at concentrations between $12-25 \mu \mathrm{M}$.

\section{Conclusions}

As a result, the compounds with the least toxic effect on $3 \mathrm{~T} 3$ fibroblast human healthy cells at a concentration of $12.5 \mu \mathrm{M}$ and the compounds with the highest toxic effect on PC3 prostate cancer cells at the same concentration were $\mathbf{5 c}, \mathbf{5 f}$ and $\mathbf{8 c}$. At $25 \mu \mathrm{M}$ concentration, the compounds with the least toxic effect on 3T3 fibroblast human healthy cells and the compounds with the highest toxic effect on PC3 prostate cancer cells at the same concentration were $5 \mathbf{c}, 5 \mathbf{5 e}, \mathbf{5 f}, \mathbf{8 e}$ and $8 \mathrm{f}$.

Considering the structures of the compounds, $\mathbf{5 c}$ and $\mathbf{8 c}$, which are more active than the others, have 18 carbons in the side chain (stearic acid ester), while $\mathbf{5 e}$ and $\mathbf{8 e}$ have 24 carbons (tetracosanoic acid ester), which means the compounds having two carbon side chains were more effective than the compounds with one carbon side chain. Thus, the most effective compound was found to have stearic acid side chain.

The compounds, synthesized in this study, showed strong toxicity toward PC3 prostate cancer cells, even at low concentrations, and demonstrated relatively low toxicity on healthy cells. Such a result is very important for the discovery of new chemotherapeutic drugs.

\section{Acknowledgements}

This study was financially supported by Bezmialem Vakif University, Scientific Research Project Number: 4.2019/21.

\section{Supporting Information}

Supporting information accompanies this paper on http://www.acgpubs.org/journal/organic$\underline{\text { communications }}$

\section{ORCID}

Halil Şenol: 0000-0002-8333-035X

Kübra Çokuludağ: 0000-0002-0747-3084

Asude Sena Aktaş: 0000-0001-9702-7258

Sezen Atasoy: 0000-0001-5063-5053

Aydan Dağ: $0000-0002-1552-8030$

Gülaçtı Topçu: 0000-0002-7946-6545

\section{References}

[1] Anonymous, Acs releases 2005 edition of cancer facts \& figures. Am. Fam. Physician 2005, 71 (8), $1612-$ 1612 . 
[2] Hausman, D. M., What is cancer? Perspect. Biol. Med. 2019, 62 (4), 778-784.

[3] Nygren, P.; Grp, S. B. U., What is cancer chemotherapy? Acta Oncol. 2001, 40 (2-3), 166-174.

[4] Schram, F. R.; Ng, P. K. L., What is cancer? J. Crust. Biol. 2012, 32 (4), 665-672.

[5] Popat, K.; McQueen, K.; Feeley, T. W., The global burden of cancer. Best Pract. Res. Clin. Anaesthesiol. 2013, 27 (4), 399-408.

[6] Parkin, D. M.; Bray, F.; Ferlay, J.; Pisani, P., Global cancer statistics, 2002. CA Cancer J. Clin. 2005, 55 (2), 74-108.

[7] Jemal, A.; Bray, F.; Center, M. M.; Ferlay, J.; Ward, E.; Forman, D., Global cancer statistics. $C A$ Cancer J. Clin. 2011, 61 (2), 69-90.

[8] Chuang, K. Y.; Chuang, Y. C.; Ho, Y. S., Global influence of cancer statistics articles. Curr. Sci. 2015, 109 (9), 1552-1554.

[9] Bray, F.; Ferlay, J.; Soerjomataram, I.; Siegel, R. L.; Torre, L. A.; Jemal, A., Global cancer statistics 2018: Globocan estimates of incidence and mortality worldwide for 36 cancers in 185 countries. $C A$ Cancer J. Clin. 2018, 68 (6), 394-424.

[10] Zorlu, F.; Divrik, R. T.; Eser, S.; Yorukoglu, K., Prostate cancer incidence in Turkey: An epidemiological study. Asian Pac. J. Cancer Prev. 2014, 15 (21), 9125-9130.

[11] Attard, G.; Parker, C.; Eeles, R. A.; Schroder, F.; Tomlins, S. A.; Tannock, I.; Drake, C. G.; de Bono, J. S., Prostate cancer. Lancet 2016, 387 (10013), 70-82.

[12] Ilic, D.; Dahm, P., Prostate cancer screening in europe. Lancet 2015, 385 (9977), 1506-1506.

[13] Dzubak, P.; Hajduch, M.; Vydra, D.; Hustova, A.; Kvasnica, M.; Biedermann, D.; Markova, L.; Urban, M.; Sarek, J., Pharmacological activities of natural triterpenoids and their therapeutic implications. Nat. Prod. Rep. 2006, 23 (3), 394-411.

[14] Zhang, Q.; Chang, Z.; Wang, Q., Ursane triterpenoids inhibit atherosclerosis and xanthoma in ldl receptor knockout mice. Cardiovasc. Drugs Ther. 2006, 20 (5), 349-357.

[15] Ukiya, M.; Akihisa, T.; Tokuda, H.; Suzuki, H.; Mukainaka, T.; Ichiishi, E.; Yasukawa, K.; Kasahara, Y.; Nishino, H., Constituents of compositae plants III. Anti-tumor promoting effects and cytotoxic activity against human cancer cell lines of triterpene diols and triols from edible chrysanthemum flowers. Cancer Lett. 2002, 177 (1), 7-12.

[16] Topcu, G., Bioactive triterpenoids from salvia species. J. Nat. Prod. 2006, 69 (3), 482-487.

[17] Liby, K. T.; Yore, M. M.; Sporn, M. B., Triterpenoids and rexinoids as multifunctional agents for the prevention and treatment of cancer. Nat. Rev. Cancer 2007, 7 (5), 357-369.

[18] Topcu, G.; Eris, C.; Ulubelen, A.; Krawiec, M.; Watson, W. H., New rearranged neoclerodane diterpenoids from Teucrium alyssifolium. Tetrahedron 1995, 51 (43), 11793-11800.

[19] Topcu, G.; Tan, N.; Ulubelen, A.; Sun, D.; Watson, W. H., Terpenoids and flavonoids from the aerial parts of Salvia candidissima. Phytochemistry 1995, 40 (2), 501-504.

[20] Topcu, G.; Ayral, M. N.; Aydin, A.; Goren, A. C.; Chai, H. B.; Pezzuto, J. M., Triterpenoids of the roots of Lavandula stoechas ssp stoechas. Pharmazie 2001, 56 (11), 892-895.

[21] Ertas, A.; Ozturk, M.; Boga, M.; Topcu, G., Antioxidant and anticholinesterase activity evaluation of ent-kaurane diterpenoids from Sideritis arguta. J. Nat. Prod. 2009, 72 (3), 500-502.

[22] Culhaoglu, B.; Yapar, G.; Dirmenci, T.; Topcu, G., Bioactive constituents of Salvia chrysophylla stapf. Nat. Prod. Res. 2013, 27 (4-5), 438-447.

[23] Culhaoglu, B.; Hatipoglu, S. D.; Donmez, A. A.; Topcu, G., Antioxidant and anticholinesterase activities of lupane triterpenoids and other constituents of Salvia trichoclada. Med. Chem. Res. 2015, 24 (11), 3831 3837.

[24] Culhaoglu, B.; Topcu, G., Biologically active lupane triterpenoids from anatolian salvia species. Planta Med. 2011, 77 (12), 1442-1442.

[25] Culhaoglu, B.; Sener, L. T.; Birman, H.; Albeniz, I.; Topcu, G., Cytotoxic effects of ursolic acid and its derivative on breast cancer cell lines. Acta Physiol. 2016, 218, 37-37.

[26] Topcu, G.; Kolak, U.; Ozturk, M.; Boga, M.; Hatipoglu, S. D.; Bahadori, F.; Culhaoglu, B.; Dirmenci, T., Investigation of anticholinesterase activity of a series of Salvia extracts and the constituents of Salvia staminea. Nat. Prod. J. 2013, 3, 3-9.

[27] Ulubelen, A.; Topcu, G., Flavonoids and terpenoids from Salvia verticillata and Salvia pinnata. J. Nat. Prod. 1984, 47 (6), 1068-1068.

[28] Ulubelen, A.; Topcu, G., Triterpenoids from Salvia pinnata. Phytochemistry 1984, 23 (1), 133-134.

[29] Topcu, G.; Turkmen, Z.; Ulubelen, A.; Schilling, J. K.; Kingston, D. G. I., Highly hydroxylated triterpenes from Salvia kronenburgii. J. Nat. Prod. 2004, 67 (1), 118-121.

[30] Topcu, G.; Ulubelen, A., Terpenoids from Salvia kronenburgii. J. Nat. Prod. 1999, 62 (12), 1605-1608.

[31] Erman, B.; Topcu, G. Inhibition of NF- $\kappa$ B activity by triterpene compounds. WO2012130481A1, 2012.

[32] Hsu, Y. L.; Kuo, P. L.; Lin, C. C., The proliferative inhibition and apoptotic mechanism of saikosaponin $\mathrm{d}$ in human non-small cell lung cancer A549 cells. Life Sci. 2004, 75 (10), 1231-1242. 
[33] Reiner, T.; Parrondo, R.; de las Pozas, A.; Palenzuela, D.; Perez-Stable, C., Betulinic acid selectively increases protein degradation and enhances prostate cancer-specific apoptosis: Possible role for inhibition of deubiquitinase activity. Plos One 2013, 8 (2),ID: e56234, DOI: 10.1371/journal.pone.0056234, 11 pages.

[34] Salminen, A.; Lehtonen, M.; Suuronen, T.; Kaarniranta, K.; Huuskonen, J., Terpenoids: Natural inhibitors of NF-Kappa B signaling with anti-inflammatory and anticancer potential. Cell. Mol. Life Sci. 2008, 65 (19), 2979-2999.

[35] Ling, H.; Jia, X. B.; Zhang, Y. C.; Gapter, L. A.; Lim, Y. S.; Agarwal, R.; Ng, K. Y., Pachymic acid inhibits cell growth and modulates arachidonic acid metabolism in nonsmall cell lung cancer a549 cells. Mol. Carcinog. 2010, 49 (3), 271-282.

[36] Kaya, B.; Kaplancıklı, Z. A.; Yurttaş, L.; Çiftçi, G. A., Synthesis and biological evaluation of some new pyrimidine bearing 2,5-disubstituted 1,3,4-oxadiazole derivatives as cytotoxic agents. Turkish J. Biochem. 2017, 42 (2), 131-137.

[37] Perrin, D. D.; Armarego, W. L., Purification of laboratory chemicals. 3th. Ed ed.; 1993.

[38] Senol, H.; Bayrak, C.; Menzek, A.; Sahin, E.; Karakus, M., Cycloaddition reaction of spiro[2.4]hepta4,6-dien-1-ylmethanol and ptad: A new rearrangement. Tetrahedron 2016, 72 (20), 2587-2592.

[39] Bayrak, C.; Senol, H.; Sirtbasi, S.; Sahin, E.; Menzek, A., Synthesis and rearrangement reactions of 1,4-dihydrospiro[1,4-methanonaphthalene-9,1'-cyclopropane] derivatives. Tetrahedron 2018, 74 (40), 5839-5849.

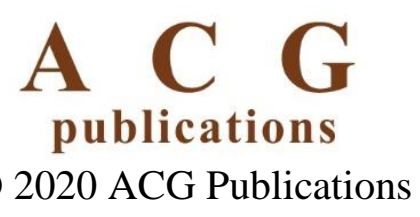

